ORIGINAL ARTICLE

\title{
Prognosis of constipation: clinical factors and colonic transit time
}

\author{
F de Lorijn, M P van Wijk, J B Reitsma, R van Ginkel, J A J M Taminiau, M A Benninga
}

Arch Dis Child 2004;89:723-727. doi: 10.1136/adc.2003.040220

See end of article for authors' affiliations

.....................

Correspondence to:

Dr F de Loriin, Department

of Paediatric

Gastroenterology and

Nutrition, Emma

Children's Hospital/

Academic Medical Centre,

Meibergdreef 9, $1105 \mathrm{AZ}$

Amsterdam, Netherlands;

f.delorijn@amc.uva.nl

Accepted

23 December 2003

\begin{abstract}
Background: Measurement of colonic transit time (CTT) is sometimes used in the evaluation of patients with chronic constipation.

Aim: To investigate the relation between symptoms and $\mathrm{CTT}$, and to assess the importance of symptoms and $\mathrm{CTT}$ in predicting outcome.

Methods: Between 1995 and 2000, 169 consecutive patients (median age 8.4 years, 65\% boys) fulfilling the criteria for constipation were enrolled. During the intervention and follow up period, all kept a diary to record symptoms. CTT was measured at entry to the study.

Results: At entry, defecation frequency was lower in girls than in boys, while the frequency of encopresis episodes was higher in boys. CTT values were significantly higher in those with a low defecation frequency $(\leqslant 1 /$ week) and a high frequency of encopresis ( $\geqslant 2 /$ day). However, $50 \%$ had CTT values within the normal range. Successful outcome occurred more often in those with a rectal impaction. CTT results $<100$ hours were not predictive of outcome. However, those with CTT $>100$ hours were less likely to have had a successful outcome.

Conclusion: The presence of a rectal impaction at presentation is associated with a better outcome at one year. A CTT $>100$ hours is associated with a poor outcome at one year.
\end{abstract}

C onstipation is a common problem in children, accounting for about $3 \%$ of consultations in an average paediatric practice and as much as $25 \%$ in a paediatric gastroenterology clinic. ${ }^{1-3}$ No specific organic cause can be found in approximately $90 \%$ of the children. ${ }^{45}$ The diagnosis is mainly based on clinical history and physical examination. Patients and/or their parents refer to the number of stools per week, to stool volume, to difficulty in defecation, and/or to sensation of abdominal fullness. ${ }^{4}$ Several tests have been developed to objectify these complaints. ${ }^{6-10}$

A plain abdominal radiograph is frequently used to confirm the presence of retained stool or enlargement of the colon or rectum. ${ }^{78}$ However, the value of abdominal $x$ ray examination in this setting is a matter of debate. ${ }^{11}$ Assessment of total and segmental colonic transit time (CTT) using radio-opaque markers, is a non-invasive method which provides information about colorectal motor function. ${ }^{6}{ }^{10}$ Furthermore, this technique has been used to localise a delayed transit in the colon and to evaluate the response to treatment. ${ }^{11-13}$ Some investigators have shown a good relation between symptoms of constipation and CTT in adults. ${ }^{14}{ }^{15}$ However, others report a significant difference between previous reported symptoms and the CTT results. ${ }^{916}$ No previous studies have investigated the prognostic value of CTT measurement.

Our study had two main objectives. First, to investigate the relation between symptoms and CTT. Second, to evaluate the possible relation between symptoms and CTT, and the outcome after one year of follow up.

\section{PATIENTS AND METHODS}

\section{Patients}

All patients referred to our paediatric gastrointestinal outpatient clinic with constipation between 1995 and 2000 were eligible. They were referred by family practitioners, paediatricians, psychiatrists, and school doctors. At entry, patients had at least two of the following: (1) defecation <3/week; (2) encopresis episodes >1/week; (3) passing of very large stool every 7-30 days; and (4) a palpable abdominal or rectal faecal mass. ${ }^{17}$ All were at least 5 years of age. Children with Hirschsprung's disease, spinal and anal anomalies, previous colon surgery, metabolic or renal abnormalities, mental retardation, or using drugs other than laxatives were excluded. All patients and parents gave written informed consent. The medical ethics committee of the hospital approved the protocol.

\section{Colonic transit time}

At entry, all children underwent a CTT study using the method described by Metcalf and colleagues. ${ }^{10}$ Treatment with oral or rectal laxatives was discontinued for at least four days before the test; during this period they took one sachet of fibre (Volcolon, $6 \mathrm{~g}$ ) each day. They then ingested a capsule with containing 20 radio-opaque markers on three consecutive mornings. Abdominal $x$ ray examinations were performed on days 4 and 7 in the morning. Additional abdominal $x$ ray examinations were performed on days 10 , 13 , and 16 if more than $20 \%$ of the markers remained on the previous film. $x$ Ray localisation of markers was based on the identification of bony landmarks and gaseous outlines as described by Arhan and colleagues. ${ }^{6}$ Markers were counted in the right, left, and rectosigmoid regions, and mean segmental transit times were calculated according to a previously described formula. ${ }^{6}{ }^{10}$ The normal ranges for total and segmental transit times were based on the upper limits (mean +2 SD) from a study in healthy children. ${ }^{6}$ Based on this study, a CTT of more than 62 hours was considered delayed. The upper limits of the normal range for right colon, left colon, and rectosigmoid transit time were 18, 20, and 34 hours, respectively. ${ }^{6}$

\section{Medical history and physical examination}

One week prior to entry and throughout the study the child and parents kept a diary in which defecation frequency,

Abbreviations: $\mathrm{CTT}$, colonic transit time; RSTT, rectosigmoid transit time; FNRFS, functional non-retentive faecal soiling 
encopresis frequency, consistency and size of stool, and pain during defecation were recorded. Associated symptoms such as abdominal pain, appetite suppression, absence of urge to defecate, and enuresis were also noted.

At entry, abdominal and rectal examinations were performed. Abdominal distension and palpable abdominal faecal masses were noted. Anal tone and the presence of a faecal impaction were recorded.

\section{Treatment and follow up}

The treatment regimens consisted of a high fibre diet, toilet advice (attempt defecation on the toilet for five minutes after meals), laxatives, and biofeedback training or anorectal manometry. ${ }^{17}$ Oral laxative therapy consisted of an initial dosage of $6 \mathrm{~g}$ lactulose per day, increased stepwise to a maximum of $24 \mathrm{~g}$ if necessary. Enemas were given if severe rectal faecal impaction was present. A reward system was also employed.

The treatment intervention lasted for eight weeks. A detailed medical history was obtained during the intervention period, and at 6 and 12 months after entry. When necessary, children were also seen at other times at the outpatient clinic.

\section{Definition of success}

Treatment was considered to be "successful" if patients had three or more bowel movements weekly and fewer than one encopresis episode in a two week period, having discontinued laxatives for at least one month.

\section{Statistical analysis}

Baseline characteristics of the cohort were analysed in a descriptive way. Median values and 25th and 75 th or 10th and 90th centiles were used if the distribution of continuous variables was skewed. Non-parametric (Mann-Whitney U and Kruskal-Wallis) and $\chi^{2}$ statistics were used to test for differences between groups. Logistic regression models were used to examine possible factors associated with success at one year. The following factors were considered: defecation frequency (in three groups: $\leqslant 1 /$ week, $1-3 /$ week, and $\geqslant 3 /$ week), encopresis frequency (in four groups: no encopresis, $<1 /$ day, $1-2 /$ day, $\geqslant 2 /$ day), the presence of night-time encopresis, the production of large stools, the presence of an abdominal or rectal mass, and CTT $>100$ hours. Odds ratios with $95 \%$ confidence intervals were used to express the strength of the associations.

\section{RESULTS}

\section{Baseline characteristics}

A total of 169 consecutive children (65\% boys) were enrolled. Table 1 presents their baseline characteristics. The median age at intake was 8.4 years. The median defecation frequency at intake was lower in girls than in boys ( $1.0 \vee 2.0$ times per week; $p=0.03$ ), while an encopresis frequency of more than twice weekly was reported more often in boys (94\% v 73\%; $p=0.0002$ ). Of the total group, $65 \%$ reported the passage of large stools every 7-30 days. Night-time encopresis occurred in $37 \%$. A rectal impaction was present in $32 \%$.

Table 2 shows the total and segmental colonic transit times at entry to the study. Approximately $50 \%$ had a total CTT in the normal range. No significant differences were found between boys and girls in the CTT or rectosigmoid transit time (RSTT). In $86 \%$ of those with an abnormal CTT, the RSTT was also prolonged. In children with a normal CTT, a delay in RSTT was present in only $14 \%$. There was a significant correlation between CTT and RSTT (Pearson correlation coefficient $0.88, \mathrm{p}=0.0002$ ).
In the total group, a CTT $>100$ hours was found in $22 \%$. Of these, $92 \%$ had a delayed RSTT and 39\% had a delay in all segments.

\section{Correlation between CTT and symptom severity}

At the first visit, children with a very low defecation frequency ( $\leqslant 1$ /week) showed significantly prolonged median CTT (74 hours) compared to children with a defecation frequency of $1-3 /$ week ( 50 hours) and a defecation frequency $\geqslant 3 /$ week ( 49 hours) $(\mathrm{p}=0.001)$. In addition, in patients with $\geqslant 2$ episodes of encopresis per day, median CTT values were significantly delayed ( 70 hours) compared to the group with 1-2 episodes of encopresis per day ( 50 hours), the group with $<1$ episode of encopresis per day ( 52 hours), and those without encopresis (49 hours) $(\mathrm{p}=0.003)$ (table 3$)$. Furthermore, a significantly higher CTT was present in children with night-time encopresis and in those with a rectal mass (respectively $\mathrm{p}<0.0001$ and $\mathrm{p}<0.0001$ ) (table 3 ). As table 3 shows, similar associations were found between clinical symptoms and rectosigmoid transit time.

\section{Clinical outcome and prognostic value}

After one year $50 \%$ of the boys and $72 \%$ of the girls had a successful outcome (relative risk (RR) boys $v$ girls 0.70 ; $95 \%$ CI 0.55 to 0.90 ). These percentages increased to $61 \%$ in boys and to $80 \%$ in girls (RR $0.77 ; 95 \%$ CI 0.63 to 0.93 ) when patients were included who had a normal defecation frequency without encopresis but where still using laxatives.

The independent effect of various prognostic factors was analysed in a multivariate model predicting the probability of a successful outcome after one year. Boys were less likely to be successfully treated at one year (OR 0.34; CI 0.16 to 0.70 ). The presence of a mass on rectal examination was a positive predictive sign for success (OR 3.39; CI 1.30 to 8.83). In those with a CTT $<100$ hours at entry, the transit time did not predict outcome at one year. However, those with a CTT $>100$ hours were less likely to have a successful outcome (OR 0.31 ; CI 0.12 to 0.85 ). Other possible prognostic factors such as a low defecation frequency, the presence of encopresis, and large stools at entry were not associated with outcome (table 4).

\section{DISCUSSION}

This study shows that more severe symptoms, such as a relatively low defecation frequency, or a high encopresis frequency and the presence of a palpable rectal mass strongly correlate with a prolonged CTT and RSTT. Gender (girls) and a palpable rectal mass at entry were associated with a successful outcome at one year. An abdominal $x$ ray examination with the use of radio-opaque markers at intake had no predictive value. Measurement of CTT did not predict outcome if less than 100 hours. In contrast, a CTT above 100 hours predicted a poor outcome at one year.

The ingestion of radio-opaque markers and the use of one or more abdominal $x$ ray examinations allow the differentiation between children with normal or prolonged CTT. ${ }^{18}$ Several techniques have been used to measure CTT in patients with gastrointestinal disorders and have proved to be reliable and reproducible. ${ }^{19}$ In our study we used the three day Metcalf marker method. $x$ Ray examinations were repeated with a three day interval until more than $80 \%$ of the markers disappeared. ${ }^{10}$ With this method, the radiation exposure is relatively high in children with severe constipation. In future studies, we will use the Bouchoucha method in which the patient ingests one capsule with 10 markers on six consecutive days. Subsequently, only one abdominal $x$ ray examination at day 7 is needed to calculate CTT. ${ }^{20}$

In this study CTT was measured without first cleansing the colon. A recent study in adults with constipation showed no 
Table 1 Baseline characteristics and clinical findings

\begin{tabular}{|c|c|c|c|c|}
\hline & $\begin{array}{l}\text { Boys } \\
n=109\end{array}$ & $\begin{array}{l}\text { Girls } \\
n=60\end{array}$ & $\begin{array}{l}\text { Total } \\
n=169\end{array}$ & Missing \\
\hline \multicolumn{5}{|l|}{ Age, years } \\
\hline Median & 8.5 & 8.0 & 8.4 & \\
\hline 25th-75th centiles & $7.0-10.5$ & $6.9-10.6$ & $7.0-10.5$ & \\
\hline \multicolumn{5}{|l|}{ Age of onset of symptoms, years } \\
\hline Median & 4.0 & 3.0 & 3.5 & \\
\hline 25 th-75th centiles & $1.0-4.0$ & $0.0-4.0$ & $1.0-4.0$ & \\
\hline \multicolumn{5}{|l|}{ Defecation frequency/week } \\
\hline Median & 2.0 & $1.0^{*}$ & 2.0 & \\
\hline 25 th-75th centiles & $1.0-3.0$ & $1.0-2.0$ & $1.0-2.0$ & \\
\hline$<3$ times/week & $74 \%$ & $88 \% \dagger$ & $79 \%$ & \\
\hline \multicolumn{5}{|c|}{ Encopresis frequency/week (daytime) } \\
\hline Median & 10.5 & 8.5 & 10.0 & \\
\hline 25th-75th centiles & $7.0-21.0$ & $1.0-21.0$ & $5.5-21.0$ & \\
\hline$\geqslant 2$ times per week & $94 \%$ & $73 \% \dagger$ & $86 \%$ & \\
\hline No encopresis & $6 \%$ & $20 \% \dagger$ & $11 \%$ & \\
\hline Night-time encopresis & $38 \%$ & $37 \%$ & $37 \%$ & \\
\hline Abdominal pain & $57 \%$ & $52 \%$ & $56 \%$ & 2 \\
\hline Pain during defecation & $45 \%$ & $47 \%$ & $46 \%$ & 2 \\
\hline No rectal sensation & $22 \%$ & $16 \%$ & $20 \%$ & 2 \\
\hline Large stools (every $7-30$ days) & $63 \%$ & $68 \%$ & $65 \%$ & \\
\hline Palpable abdominal mass & $26 \%$ & $18 \%$ & $23 \%$ & \\
\hline Palpable rectal mass & $32 \%$ & $27 \%$ & $30 \%$ & \\
\hline
\end{tabular}

difference in distribution patterns of the markers before and after cleansing of the colon. ${ }^{21}$

In agreement with previous studies in adults and children we found that severe symptoms of constipation strongly correlated with prolonged CTT and RSTT. ${ }^{12}{ }^{15} 22$ It has been suggested that constipation in children is mostly caused by the conscious or unconscious postponement of defecation (withholding behaviour). This could be learned behaviour due to pain with evacuation of a large faecal bolus. Prolonged stool retention in the rectum might result in increased anorectal sampling with failure of contraction of the external anal sphincter and consequent soiling. It is likely that the associated delay in RSTT leads to secondary prolongation of CTT.

In accordance with earlier studies in children with constipation a normal CTT was found in approximately 50\% of the patients. ${ }^{1122-24}$ It has been suggested that adults complaining of constipation with normal transit times have a high incidence of psychosocial disturbance and may not be truly constipated..$^{25}$ In children, however, van der Plas et al showed that reported symptoms correlate well with the actual bowel habit. ${ }^{26}$ In a recent study we showed that colonic transit patterns, including normal colonic transit were not indicative of abnormal behaviour. ${ }^{27}$ Normal colonic transit time in constipated children is probably due to the fact that the measurement, even though it represents bowel pattern over a one week period, still remains a snapshot observation. Furthermore, the upper time limit for normal transit, as suggested by Arhan et al, is based on only 23 healthy children, and so may be misleading. ${ }^{6}$ Papadopoulou et al suggested that the markers themselves might accelerate transit, causing a false negative result. ${ }^{13}$

In our experience this marker test has proved useful in differentiating retentive from non-retentive defecation disorders, such as constipation and functional non-retentive faecal soiling. ${ }^{28}$ A normal CTT in combination with a normal defecation frequency and no rectal mass indicates the latter diagnosis. ${ }^{22}$ Such children are best treated with a toilet training programme without laxatives. ${ }^{29}$ Furthermore, treatment of CTT is useful in cases in which information is unreliable, such as in eating disorders.

Table 2 Total and segmental transit times

\begin{tabular}{|c|c|c|c|}
\hline & \multicolumn{3}{|c|}{ Transit time, hours } \\
\hline & $\begin{array}{l}\text { Boys } \\
(n=109)\end{array}$ & $\begin{array}{l}\text { Girls } \\
(n=60)\end{array}$ & $\begin{array}{l}\text { Total group } \\
(n=169)\end{array}$ \\
\hline \multicolumn{4}{|l|}{ Total colon } \\
\hline Median & 60 & 53 & 58 \\
\hline $25-75$ th centiles & $38-103$ & $37-74$ & $37-92$ \\
\hline Delayed $>62$ hours & $49 \%$ & $43 \%$ & $47 \%$ \\
\hline \multicolumn{4}{|l|}{ Ascending colon } \\
\hline Median & 10 & 11 & 10 \\
\hline $25-75$ th centiles & $5-16$ & $5-15$ & $5-16$ \\
\hline Delayed $>18$ hours & $23 \%$ & $18 \%$ & $21 \%$ \\
\hline \multicolumn{4}{|l|}{ Descending colon } \\
\hline Median & 11 & 8 & 10 \\
\hline $25-75$ th centiles & $4-18$ & $5-18$ & $5-18$ \\
\hline Delayed $>20$ hours & $21 \%$ & $23 \%$ & $22 \%$ \\
\hline \multicolumn{4}{|l|}{ Rectosigmoid } \\
\hline Median & 37 & 31 & 32 \\
\hline $25-75$ th centiles & $19-68$ & $17-47$ & $18-63$ \\
\hline Delayed $>34$ hours & $53 \%$ & $38 \%$ & $48 \%$ \\
\hline
\end{tabular}


Table 3 Correlation between clinical parameters and transit time (hours)

\begin{tabular}{|c|c|c|c|c|c|}
\hline & No. of patients & $\mathrm{CTT}$ (median) & $\mathrm{p}$ value & RSTT (median) & p value \\
\hline \multicolumn{6}{|c|}{ Defecation frequency } \\
\hline $0-1 /$ week & 79 & 74 & $0.001^{*}$ & 38 & $0.009^{*}$ \\
\hline$>1-3 /$ week & 55 & 50 & & 30 & \\
\hline$\geqslant 3 /$ week & 35 & 49 & & 28 & \\
\hline \multicolumn{6}{|c|}{$\begin{array}{l}\text { Encopresis frequency (day and } \\
\text { night) }\end{array}$} \\
\hline No encopresis & 18 & 49 & $0.003^{*}$ & 24 & $0.03^{*}$ \\
\hline$<1 /$ day & 24 & 52 & & 31 & \\
\hline $1-2 /$ day & 48 & 50 & & 30 & \\
\hline$\geqslant 2 /$ day & 79 & 70 & & 38 & \\
\hline \multicolumn{6}{|c|}{ Night-time encopresis } \\
\hline Not present & 106 & 47 & $<0.0001 \dagger$ & 28 & $<0.0001 \dagger$ \\
\hline Present & 63 & 74 & & 46 & \\
\hline \multicolumn{6}{|l|}{ Rectal mass } \\
\hline Not present & 118 & 48 & $<0.0001 \dagger$ & 28 & $<0.0001 \dagger$ \\
\hline Present & 51 & 86 & & 64 & \\
\hline
\end{tabular}

Table 4 Prognostic factors for those cured at one year

\begin{tabular}{|c|c|}
\hline & $\begin{array}{l}\text { Multivariate analysis } \\
\text { Odds ratio }(95 \% \mathrm{Cl})\end{array}$ \\
\hline Male & $0.34(0.16$ to 0.70$)$ \\
\hline \multicolumn{2}{|l|}{ Defecation frequency } \\
\hline$\geqslant 3 /$ week & 1.00 (reference) \\
\hline$>1-3 /$ week & $1.48(0.54$ to 4.08$)$ \\
\hline $0-1 /$ week & $1.06(0.40$ to 2.80$)$ \\
\hline \multicolumn{2}{|l|}{ Encopresis frequency } \\
\hline No encopresis & 1.00 (reference) \\
\hline$<1 /$ day & 0.58 (0.14 to 2.43$)$ \\
\hline 1-2/day & 0.44 (0.11 to 1.68$)$ \\
\hline$\geqslant 2 /$ day & 0.44 (0.12 to 1.68$)$ \\
\hline Large stools & $1.09(0.51$ to 2.30$)$ \\
\hline Night-time encopresis & $1.10(0.51$ to 2.41$)$ \\
\hline Palpable abdominal mass & $1.23(0.49$ to 3.10$)$ \\
\hline Palpable rectal mass & 3.39 (1.30 to 8.83$)$ \\
\hline $\mathrm{CTT}>100$ hours & $0.31(0.12$ to 0.85$)$ \\
\hline
\end{tabular}

After one year, $58 \%$ of the patients in our study had been treated successfully. This was in accordance with success rates in other long term follow-up studies. ${ }^{30-32}$ The overall success rate was $68 \%$ when patients without symptoms of constipation were included. In a recent long term study, more than $50 \%$ of the children with constipation experienced at least one relapse within the five years of first treatment. ${ }^{33}$

To our surprise, the presence of a rectal mass at presentation was a positive predictor of success. After removal of the mass most children experience less pain with defecation. It is likely that rectal control of sensation and defecation improves after removal, and there is a decrease in encopresis and abdominal pain.

A CTT longer than 100 hours predicted a poor outcome at one year. Almost $40 \%$ of these children had a delay in transit in all segments. Some patients, mainly adolescent girls, might suffer from idiopathic slow transit constipation. ${ }^{34-36}$ This severe form of constipation presents with a gradual reduction in bowel frequency and increasing abdominal pain.

In conclusion, the diagnostic and prognostic role of CTT measurements is limited. Only those with a CTT above 100 hours have a predictably poor outcome.

\section{Authors' affiliations}

F de Lorijn, M P van Wijk, R van Ginkel, J A J M Taminiau, M A Benninga, Department of Paediatric Gastroenterology and Nutrition, Emma Children's Hospital/Academic Medical Centre, Amsterdam, Netherlands
J B Reitsma, Department of Clinical Epidemiology and Biostatistics, Academic Medical Centre, Amsterdam, Netherlands

\section{REFERENCES}

1 Loening-Baucke V. Chronic constipation in children. Gastroenterology 1993; 105: 1557-64

2 Levine MD. Children with encopresis: a descriptive analysis. Pediatrics 1975:56:412-16.

3 Taitz LS, Wales JK, Urwin OM, et al. Factors associated with outcome in management of defecation disorders. Arch Dis Child 1986;61:472-7.

4 Hinton JM, Lennard-Jones JE. Constipation: definition and classification. Postgrad Med J 1968;44:720-3.

5 Hinton JM, Lennard-Jones JE, Young AC. A new method for studying gut transit times using radioopaque markers. Gut 1969;10:842-7.

6 Arhan P, Devroede G, Jehannin B, et al. Segmental colonic transit time. Dis Colon Rectum 1981;24:625-9.

7 Barr RG, Levine MD, Wilkinson RH, et al. Chronic and occult stool retention: a clinical tool for its evaluation in school-aged children. Clin Pediatr (Phila) 1979;18:674-9.

8 Rockney RM, McQuade WH, Days AL. The plain abdominal roentgenogram in the management of encopresis. Arch Pediatr Adolesc Med 1995:149:623-7.

9 Chaussade S, Khyari A, Roche $H$, et al. Determination of total and segmental colonic transit time in constipated patients. Results in 91 patients with a new simplified method. Dig Dis Sci 1989;34:1 168-72.

10 Metcalf AM, Phillips SF, Zinsmeister AR, et al. Simplified assessment of segmental colonic transit. Gastroenterology 1987;92:40-7.

11 Benninga MA, Buller HA, Staalman CR, et al. Defecation disorders in children, colonic transit time versus the Barr-score. Eur J Pediatr 1995; 154:277-84.

12 Benninga MA, Buller HA, Tytgat GN, et al. Colonic transit time in constipated children: does pediatric slow-transit constipation exist? J Pediatr Gastroenterol Nutr 1996;23:241-51.

13 Papadopoulou A, Clayden GS, Booth IW. The clinical value of solid marker transit studies in childhood constipation and soiling. Eur J Pediatr 1994; 153:560-4.

14 Glia A, Lindberg G, Nilsson $\mathrm{LH}$, et al. Clinical value of symptom assessment in patients with constipation. Dis Colon Rectum 1999;42:1401-8.

15 Verduron A, Devroede G, Bouchoucha M, et al. Megarectum. Dig Dis Sci 1988;33:1164-74.

16 Mollen RM, Claassen ATPM, Kuijpers JHC. [Measurement of colon transit time useful in the evaluation of functional constipation] [Dutch]. Ned Tijdschr Geneeskd 1998;142:357-61.

17 van der Plas RN, Benninga MA, Buller HA, et al. Biofeedback training in treatment of childhood constipation: a randomised controlled study. Lancet 1996;348:776-80.

18 Aggarwal A, Cutts TF, Abell TL, et al. Predominant symptoms in irritable bowel syndrome correlate with specific autonomic nervous system abnormalities. Gastroenterology 1994;106:945-50.

19 Nam YS, Pikarsky AJ, Wexner SD, et al. Reproducibility of colonic transit study in patients with chronic constipation. Dis Colon Rectum 2001 ;44:86-92.

20 Bouchoucha M, Devroede G, Arhan P, et al. What is the meaning of colorectal transit time measurement? Dis Colon Rectum 1992;35:773-82.

21 Sloots CE, Felt-Bersma RJ. Effect of bowel cleansing on colonic transit in constipation due to slow transit or evacuation disorder. Neurogastroenterol Motil 2002; 14:55-61.

22 Benninga MA, Buller HA, Heymans HS, et al. Is encopresis always the result of constipation? Arch Dis Child 1994;71:186-93.

23 Wald A. Colonic transit and anorectal manometry in chronic idiopathic constipation. Arch Intern Med 1986;146:1713-16.

24 Gutierrez C, Marco A, Nogales A, et al. Total and segmental colonic transit time and anorectal manometry in children with chronic idiopathic constipation. J Pediatr Gastroenterol Nutr 2002;35:31-8. 
25 Wald A, Hinds JP, Caruana BJ. Psychological and physiological characteristics of patients with severe idiopathic constipation. Gastroenterology
$1989 ; 97: 932-7$.

26 van der Plas RN, Benninga MA, Redekop WK, et al. How accurate is the recall of bowel habits in children with defecation disorders? Eur J Pediatr 1997; 156:178-81.

27 Benninga MA, Voskuij WP, Akkerhuis GW, et al. Colonic transit times and behaviour profiles in children with defecation disorders. Arch Dis Child 2004;89:13-16.

28 Louvel D, Delvaux M, Felez A, et al. Oxytocin increases thresholds of colonic visceral perception in patients with irritable bowel syndrome. Gut 1996;39:741-7

29 van Ginkel R, Benninga MA, Blommaart PJ, et al. Lack of benefit of laxatives as adjunctive therapy for functional nonretentive fecal soiling in children. J Pediatr 2000;137:808-13.

30 Sutphen JL, Borowitz SM, Hutchison RL, et al. Long-term follow-up of medically treated childhood constipation. Clin Pediatr (Phila) 1995;34:576-80.
31 Loening-Baucke V. Constipation in early childhood: patient characteristics, treatment, and longterm follow up. Gut 1993;34:1400-4.

32 Keuzenkamp-Jansen CW, Fijnvandraat CJ, Kneepkens CM, et al. Diagnostic dilemmas and results of treatment for chronic constipation. Arch Dis Child 1996:75:36-41.

33 van Ginkel R, Reitsma JB, Buller HA, et al. Childhood constipation: longitudinal follow-up beyond puberty. Gastroenterology 2003; 125:357-63.

34 Preston DM Lennard-Jones JE. Severe chronic constipation of young women: 'idiopathic slow transit constipation'. Gut 1986;27:41-8.

35 Schouten WR, Ten Kate FJ, de Graaf EJ, et al. Visceral neuropathy in slow transit constipation: an immunohistochemical investigation with monoclonal antibodies against neurofilament. Dis Colon Rectum 1993:36:1112-17.

36 Wedel T, Spiegler J, Soellner S, et al. Enteric nerves and interstitial cells of Cajal are altered in patients with slow-transit constipation and megacolon. Gastroenterology 2002;123:1459-67.
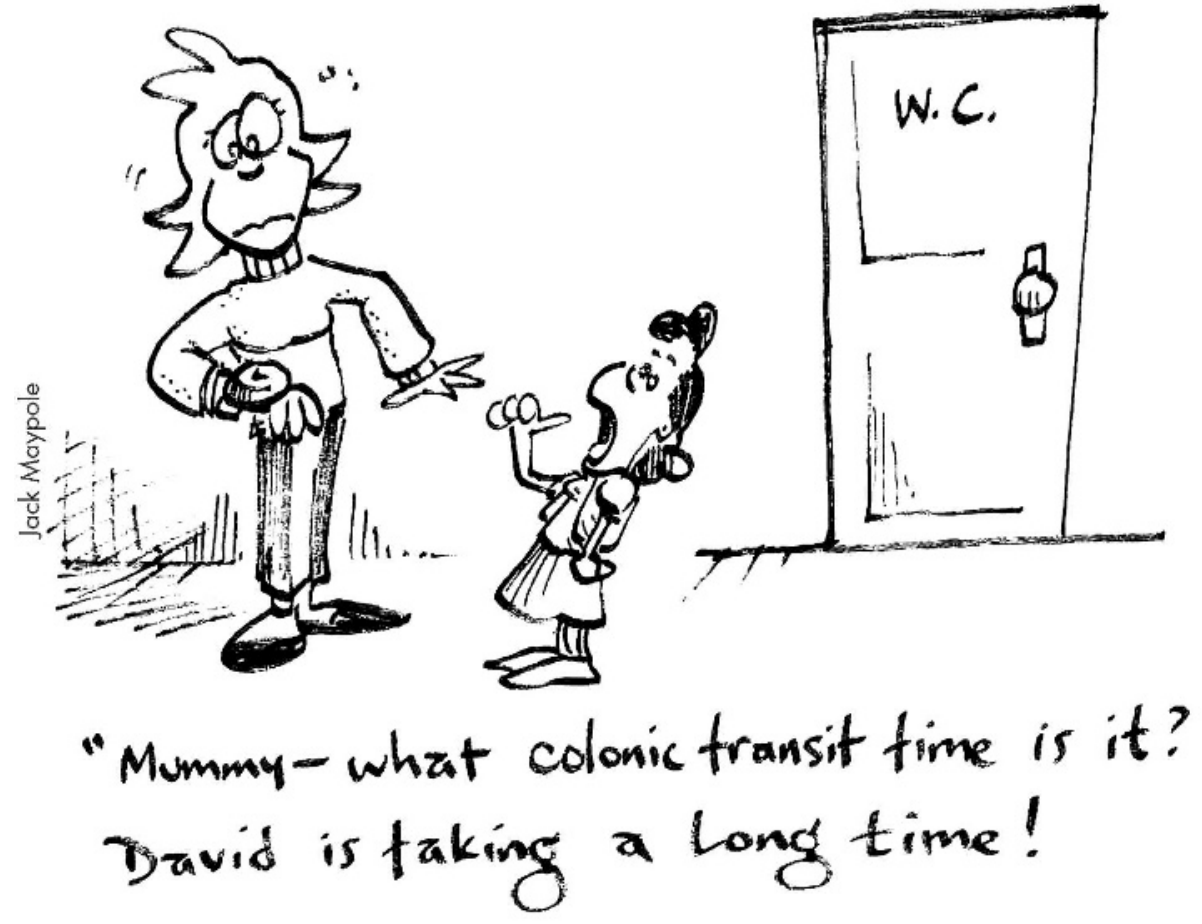